\title{
Just for fun?
}

\section{Working out why animals play is no easy task.}

\section{The Genesis of Animal Play: \\ Testing the Limits \\ by Gordon M. Burkhardt \\ MIT Press: 2005. 518 pp. \$50, $£ 32.95$}

\section{Bernd Heinrich}

A kitten batting a ball of yarn, kids on a swing, or an adult wielding a fishing-rod few would disagree that these behaviours can be described as play. Yet in the study of animal behaviour, the phenomenon of play is an anomaly. It is said to be adaptive and yet it involves the expenditure of much energy, often with no apparent pay-off. When a certain behaviour is found to have obvious pay-offs or functions it is, almost by definition, no longer 'play' but is defined by its function, such as foraging, predator avoidance or mating.

According to the simplest, most shortterm definition, play is 'just for fun'. But in the long term it may also be practice for a future role, although the ultimate pay-off may only be determined over a lifetime. Consider the activity of batting a ball around. That's play, isn't it? But if someone got paid for it, would it still be play? Even without pay, it may be for practice. And what about others who expend time and resources to watch this senseless activity? It would be difficult to assign adaptive value to these behaviours, or to measure them objectively. Should play then be defined by internal motivation pleasure, fun? But the motivation of internal pleasure can apply to many complex behaviours, such as hunting, birdsong, sex or chasing a frisbee, although only the latter is likely to be called 'play'. Is play then only 'senseless' behaviour, or is it simply behaviour for which an ultimate function has yet to be discovered?

Play may be plagued by paradoxes and enigmas, but it is a genuine behavioural phenomenon. It is an appropriate subject for enquiry, if only because we know so little about it, despite the interest of scholars who for centuries have tried to define it, fix its boundaries and fathom its functions. For the most part there has been little progress instead, the subject has become entangled in a web of definitions and controversies. It is clearly time to re-examine play.

The Genesis of Animal Play does not really explore the limits that I allude to above, but to date it is the most comprehensive and illuminating effort to come to terms with this enigmatic topic. Even though Gordon Burkhardt claims his book "is not meant to be a thorough review of play research in animals or people on either a narrow or broad scale", I believe nevertheless that it does

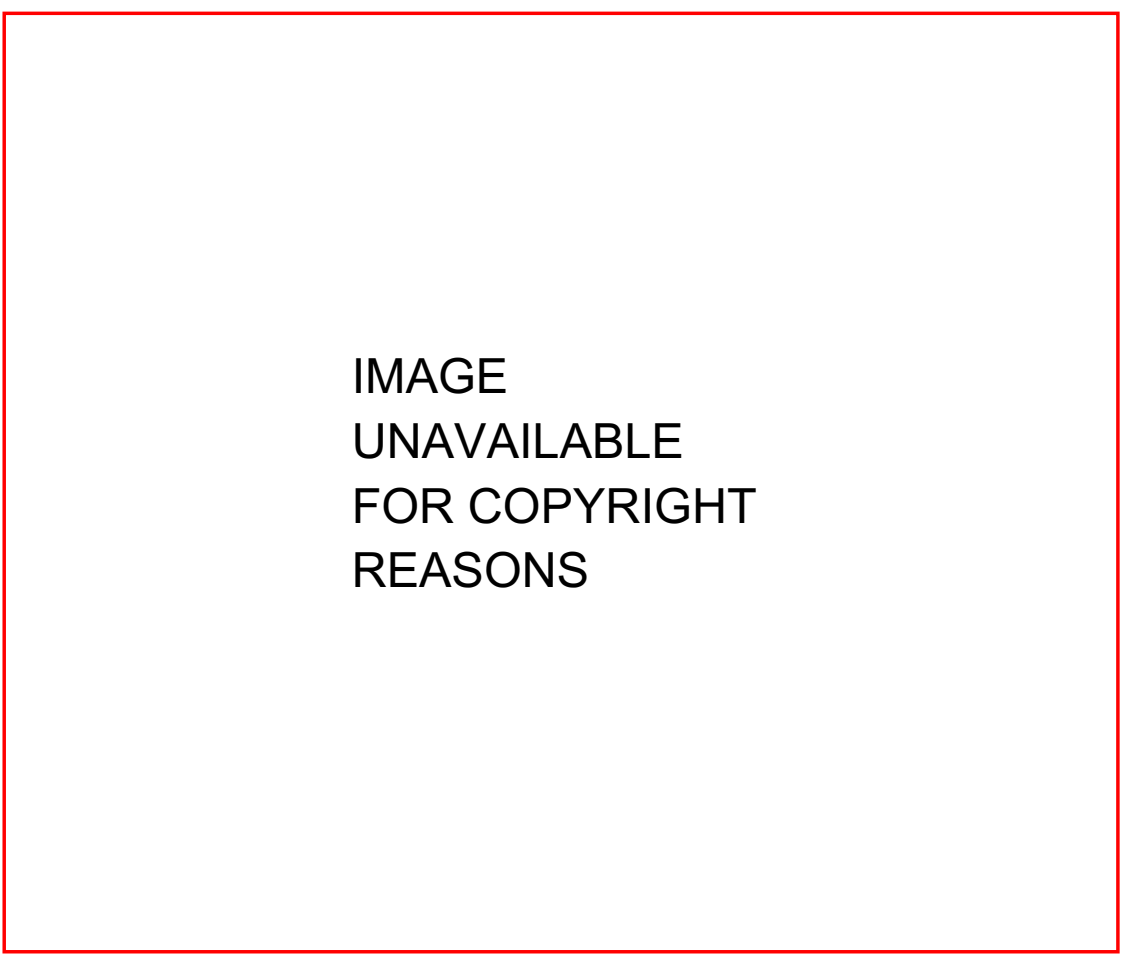

Dolphins are thought to engage in play-fighting — but is it just for fun or does practice make perfect?

come close. Burkhardt reviews the literature (about 1,300 references are cited) and refers to most of the serious attempts to study play. In his attempt to understand its origins and nature, he incorporates both comparative and multidisciplinary approaches.

In the first part of the book, Burkhardt explores the diversity of play behaviour and the history of various theories, definitions and controversies surrounding it. $\mathrm{He}$ also proposes criteria for a modern definition of play. He champions the view of ethology laid down by Niko Tinbergen, which says that any definition of a behaviour must encompass four entirely different types of problem: its causation or mechanisms; its adaptation or function; its development or ontogeny; and its evolution and phylogeny. Burkhardt adds a fifth category: the world of private experience. Researchers using this last criterion would ask whether all play is accompanied by one or a few specific emotions (presumably after play has already been identified, not to identify it).

In the second half of the book, Burkhardt examines the phylogeny of play, reviewing examples from studies of mammals, birds, reptiles, fish and invertebrates. Most of the examples of play in the literature come from a small number of placental mammals, in which play is clear-cut. However, because the focus of the book is the origin and function of play, the most relevant examples are those at the boundaries where play is not readily distinguished from non-play. Even among the mammals and the few birds studied, there is a great variety of play or potential play behaviour, so ecological, social and other potentially relevant factors may shed light even within this narrow taxonomic grouping. At the borders, in fish and invertebrates, descriptions of putative play behaviour remain anecdotal. I suspect that few of these will sustain the five criteria for play that the author sets up, but he remains open-minded to the possibility.

Burkhardt concludes by strongly backing the 'surplus resources' theory as a way to predict where and when we might expect to find playful behaviour. This idea is an elaboration of one proposed in 1795 by the German playwright Friedrich Schiller, who wrote: "An animal may be said to be at work when the stimulus to activity is some lack, and it may be said to be at play when the stimulus is sheer plenitude of vitality." Schiller's idea was further elaborated by Herbert Spencer in 1872 . Burkhardt brings it into the social context and adds the adaptive significance - that play not only originates from, but also creates, surplus resources that may be useful on subsequent occasions. I am not sure how or at what point in the life of an animal such surplus resources would 
manifest themselves or how an ethologist could demonstrate their existence. However, the idea surely applies to the activity of scientific research, and perhaps even to the writing of a book.

Bernd Heinrich is in the Department of Biology,

University of Vermont, Burlington,

Vermont 05405, USA

\section{To infinity and beyond!}

\section{Parallel Worlds: The Science of Alternative Universes and Our Future in the Cosmos \\ by Michio Kaku \\ Allen Lane/Doubleday: 2005. 448 pp. $£ 20 / \$ 27.95$}

\section{David Lindley}

Michio Kaku is an enthusiast. In the breathless introductory chapters of Parallel Worlds, he speeds through the history of cosmology and fundamental physics to persuade us that science has never been as thrilling as it is now. Edmund Halley may have been "shocked beyond belief" and "staggered" by Newton's calculation of planetary orbits, but that's small potatoes compared with the staggering science that goes on nowadays. String theory is staggering; quantum computers are truly staggering; the recent discovery of accelerating cosmic expansion left scientists dumbfounded; their minds reel at the idea of parallel universes. And when they're not reeling and staggering, they have to contend with the "insane conclusions of quantum theory".

Melodrama aside, Kaku's book provides a sprightly and generally efficient account of our present understanding of the Universe, in which astronomical observation and elementary physics combine to give a coherent, if rather bizarre, picture of the cosmos. Plain ordinary matter, such as we are made of, is tame stuff. The Universe is mostly dark matter and dark energy, both revealed by the dynamics of galaxies. As yet there is no convincing explanation for either.

But string theory will take care of that Beginning with the now familiar idea that all particles are in fact little wiggly loops inhabiting extra dimensions, Kaku sketches how gravity may one day be unified with quantum mechanics. Then we will understand space-time and all the matter and forces in it. There was a time when string theory seemed unique: only one version of it could possibly work. But more versions appeared, to be subsumed some years later into M-theory, which unifies string theories at the cost of introducing fundamental surfaces of higher dimensions (called 'branes').

It is a little unsettling now to learn that

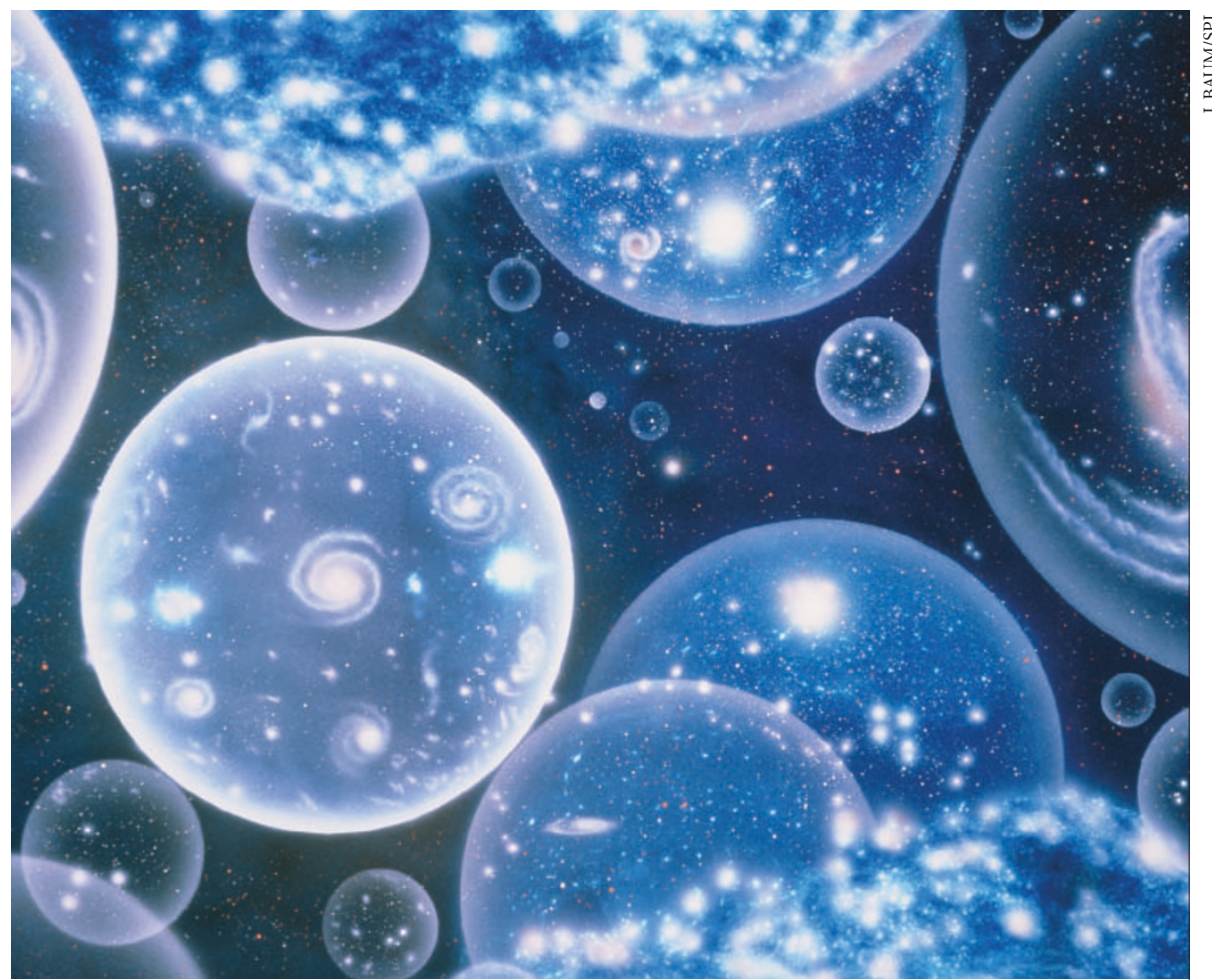

Brane teaser: if parallel universes exist, they might take the form of bubbles in different dimensions.

physicists are drowning in branes, as Kaku puts it, and that they are beginning to think that M-theory itself must be part of some yet more basic theory that is awaiting discovery. This is progress, Kaku assures us.

Although he has every confidence that the quest for a theory of everything will succeed, perhaps in just a few decades, Kaku is vague about what success will look like. $\mathrm{He}$ describes how observations of gravitational waves or of temperature fluctuations in the cosmic microwave background, or perhaps experiments at CERN's upcoming Large Hadron Collider, might reveal tiny signs of M-theory seeping from higher dimensions into our own poor world. Then again, they might not, in which case we have to fall back on neopythagorean arguments of pure mathematical consistency to let us know which is the right theory. If that theory is unique, we would "know the mind of God", says Kaku, borrowing a favourite phrase of Einstein's. Or there could be lots of legitimate theories, so that our Universe would be merely one of many possible universes. (I suppose this means that even God couldn't make his mind up.)

Whatever universe we live in, it is bound to end badly. Stars die and cosmic expansion can only lead to a cold, utterly attenuated emptiness. But we can escape this dreary fate, Kaku says. Once physicists have figured out the theory of everything, they will be able to manipulate space-time to create a wormhole through which we can pass to a new universe and start over again. Or maybe, if it is too difficult to send our physical selves to another universe, we can capture our civilization's entire sum of information and convey it down the wormhole in the memory of a quantum nanobot. This is the big payoff: by fully understanding physics, intelligence can escape its cosmic doom.

Parallel Worlds slides from even-handed discussion of what physicists and cosmologists are actually doing into areas that are, shall we say, a touch speculative. Kaku mentions problems and difficulties along the way, but he gives the distinct impression that the prospects described in his final chapters are, if not exactly within our grasp, at least reasonable extrapolations. Some readers will no doubt be entranced by the grand vision, the great sweep of imagination. For me, the parade of mind-boggling ideas breezily portrayed here - the Big Bang as a collision of branes, time travel around massive rotating cylinders, matter as holographic projection from higher to lower dimensions - created a different cumulative impression. The great enterprise of fundamental physics began to seem larky, whimsical and not quite serious.

String theory and its cosmological implications embody, for the moment, a research programme much more than a genuine theory of physics. Getting from one to the other demands detailed and diligent effort. There is no guarantee that it will all work out as desired. But Kaku takes the truth of the big ideas more or less for granted, and races ahead to the most far-reaching and literally cosmic conclusions. This is intellectual entertainment — brane candy, if you like but will it ever be more than that? David Lindley is a freelance science writer in Alexandria, Virginia, USA. 
useful. This discussion is pertinent not only to wildlife science but to all spheres of enquiry.

Lewis does not mince his words. For instance, he observes that neither Raghavendra Gadagkar of the Centre for Ecological Sciences in Bangalore nor US ecologists such as E. O. Wilson "are willing to abandon theoretical ecology to take up taxonomy though. Gadagkar encourages students to do so, and Wilson ecologists of the developing world to do the same. Neither will do it himself." And while talking about differences between India and the West, he writes that villages in India, "even those who lose crops and occasionally relatives, have existed in close contact with dangerous wildlife for centuries without driving those animals to extinction. Before the British there was no evidence of Indian 'predator elimination hunts' in the style of the Texas rattlesnake drives or the turn-of-the-century wolf bounties in the United States, aimed at the eradication of every member of a given species." There is something irresistibly refreshing about Lewis's willingness to speak his mind.

In keeping with his seemingly earnest desire to faithfully reproduce all his findings, all of his conversations (or rather, the relevant sections of them) seem to be recorded verbatim. The book is thus peppered with quotes in 'Hinglish', and misplaced modifiers, fractured sentence construction and other endearing linguistic idiosyncrasies are rife.

Despite its scholarly character, this book is user-friendly for lay-readers, thanks in no small measure to the author's superb storytelling ability. The more informed reader might skip over a couple of pages here and there with a 'been there, done that' shrug, but I suspect that few ecologists are privy to the intricate history of their chosen field of work. The book thus serves to round out their education by providing a historical and philosophical perspective.

Deepak Apte is head of the Conservation Department, Bombay Natural History Society, Hornbill House, S. B. Singh Road,

Mumbai 400 023, India.

\section{Erratum}

We apologize to Gordon M. Burghardt for misspelling his name in the recent review of his book The Genesis of Animal Play (Nature 434, 273-274; 2005).

\section{Science and superstition}

\section{Thomas Heatherwick's sculpture for the Wellcome Trust's new building in London.}

\section{Martin Kemp}

Foyer sculptures - those big lumps of arty stuff commissioned to hang or stand in the entrance spaces of large modern buildings - don't tend to occupy a high rank in the pantheon of contemporary art. There is often an inverse relationship between the size of the object and the attention it commands from those who come and go. Generally decided by committees, which are inherently uncreative, these sculptures typically occupy an unsatisfying middle ground: just modern enough to seem adventurous without imposing themselves demandingly on the viewer.

In this context, it is good to see that the massive piece commissioned from Thomas Heatherwick, which adorns a seven-story space in the Wellcome Trust's new headquarters in London (designed by Hopkins Architects), is a technical, visual and conceptual tour de force.

The statistics are impressive enough in themselves: there are almost 150,000 glass spheres; 26,732 stainless steel wires, $0.5 \mathrm{~mm}$ in diameter, and the same number of springs; the sculpture is nearly 30 metres in height; and it has a total weight of 14 tonnes. Needless to say, such a work is not the product of an archetypal artist working in romantic isolation in a studio-garret. The teamwork required is akin to that in the workshop of a major Renaissance artist-engineer.

Even more impressive, for those who enter, leave and pass by the building, are the beguiling visual effects and complex associations embedded within the sculpture. Each of the glass beads is composed of two hemispheres surrounding a piece of dichroic film that generates a range of floating effects, from clear to turquoise, pink, green, yellow, violet and orange. The glass and film together ensure that the visual impact is continually transformed as the light changes and the spectator moves through the space.

The overall form is the result of a self-organizing process. Heatherwick and his team experimented with a range of viscous molten substances, dropping them into water and watching them solidify in shapes that are unpredictable yet observe certain material parameters. Such configurations, suggestive of organic entities, were among those considered by D'Arcy Thompson in his great 1917 book, On Growth and Form. Metal proved most amenable, and, after some 400 tests, a small piece of solidified white metal was selected. This small model was then translated digitally by a screen matrix into an overall configuration of suspended beads.

The work that arose from this process does not have one single meaning. The parameters of interpretation are set in part by its presence in the headquarters of one of the world's major medical research charities. Parallels of the structure with molecular models are almost inescapable.

The German title, Bleigiessen, has strong associations with health. 'Lead-guessing' is a New Year's Eve ritual in central Europe. Molten lead is poured into water and the resulting shapes are divined as signalling a person's fortune. Yet Heatherwick did not intend this as a meaning from the beginning. It was only late in the process of design that he learnt about 'lead-pouring' from his German grandmother.

The end result is that the inherent unpredictability of the process of cooling molten metal in water belongs simultaneously to modern science and to folk intuitions about the vagaries of fortune that govern all our lives. Henry Wellcome, founder of the trust, would have been delighted by this unanticipated conjunction of modern scientific knowledge with the superstitions behind traditional customs.

Martin Kemp is professor of the history of art at the University of Oxford, Oxford OX1 1PT, UK, and co-director of Wallace Kemp Artakt.

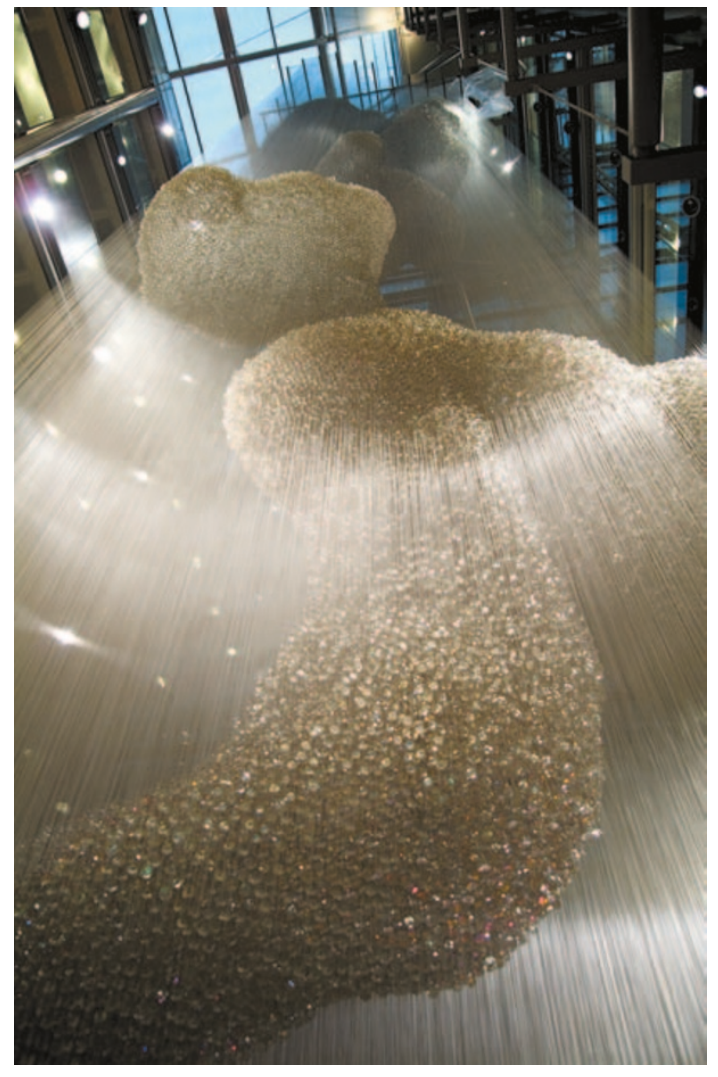

